Portland State University

PDXScholar

$11-2009$

\title{
Effects of Sea-Surface Conditions on Passive Fathometry and Bottom Characterization
}

\author{
Steven L. Means \\ Naval Research Laboratory \\ Martin Siderius \\ Portland State University, siderius@pdx.edu
}

Follow this and additional works at: https://pdxscholar.library.pdx.edu/ece_fac

Part of the Electrical and Computer Engineering Commons

Let us know how access to this document benefits you.

\section{Citation Details}

Means, S., \& Siderius, M. (2009). Effects of sea-surface conditions on passive fathometry and bottom characterization. The Journal of The Acoustical Society of America, 126(5), 2234-2241.

This Article is brought to you for free and open access. It has been accepted for inclusion in Electrical and Computer Engineering Faculty Publications and Presentations by an authorized administrator of PDXScholar. Please contact us if we can make this document more accessible: pdxscholar@pdx.edu. 


\title{
Effects of sea-surface conditions on passive fathometry and bottom characterization
}

\author{
Steven L. Means ${ }^{a)}$ \\ Naval Research Laboratory, Code 7120, 4555 Overlook Avenue SW, Washington, DC 20375 \\ Martin Siderius \\ Maseeh College of Engineering and Computer Science, Portland State University, P.O. Box 751, Portland, \\ Oregon 97207
}

(Received 6 March 2009; revised 6 August 2009; accepted 6 August 2009)

\begin{abstract}
Recently, a method has been developed that exploits the correlation properties of the ocean's ambient noise to measure water depth (a passive fathometer) and seabed layering [M. Siderius et al., J. Acoust. Soc. Am. 120, 1315-1323 (2006)]. This processing is based on the cross-correlation between the surface noise and the echo return from the seabed. To quantitatively study the dependency between processing and environmental factors such as wind speed, measurements were made using a fixed hydrophone array while simultaneously characterizing the environment. The measurements were made in 2006 in the shallow waters $(25 \mathrm{~m})$ approximately $75 \mathrm{~km}$ off the coast of Savannah, GA. A Navy tower about $100 \mathrm{~m}$ from the array was used to measure wind speed and to observe the sea-surface using a video camera. Data were collected in various environmental conditions with wind speeds ranging from 5 to $21 \mathrm{~m} / \mathrm{s}$ and wave heights of $1-3.4 \mathrm{~m}$. The data are analyzed to quantify the dependency of passive fathometer results on wind speeds, wave conditions, and averaging times. One result shows that the seabed reflection is detectable even in the lowest wind conditions. Further, a technique is developed to remove the environmental dependency so that the returns estimate seabed impedance. [DOI: 10.1121/1.3216915]
\end{abstract}

PACS number(s): 43.30.Pc, 43.30.Wi, 43.60.Pt [AIT]

Pages: 2234-2241

\section{INTRODUCTION}

In most sonar signal processing applications, ambient noise is considered a negative entity. Generally, ideal conditions for sonars are those where the ambient noise is very low. However, in recent years techniques have been developed to exploit the ambient noise field for useful applications. ${ }^{1,2}$ Recently a new method of processing ambient noise measurements has allowed for the extraction of information about the sea bottom. ${ }^{3}$ Specifically, this new method makes it possible to measure water depth (a fathometer) and seabed layering using just the ambient noise field. There are several good reasons to study techniques that use ocean noise rather than sound projectors as with traditional active sonar methods. For one, the controversy over the effects of man-made sounds on marine life highlights the need for environmentally friendly remote sensing tools such as these ambient noise systems. Further, using ambient noise rather than high-powered, man-made sound sources simplifies the measurements.

The passive fathometer methodology developed by Siderius et al. ${ }^{3}$ exploits processing the coherent components of the noise field. The passive fathometer is based on the crosscorrelation between the surface "signal," generated by breaking waves, and the echo return from the seabed. The "signal level" depends on the nature of the breaking waves, which in turn depends on other environmental factors such as wind

\footnotetext{
a) Author to whom correspondence should be addressed. Electronic mail: steve.means@nrl.navy.mil
}

speed and fetch. For practical applications with, for example, autonomous systems, it is critical to understand the parameters important to the signal processing, for example, averaging times, time snapshot size, and required sea-state. To study these parameters quantitatively, a fixed hydrophone array together with careful measurements of the environment is essential. A moving system has too many variables changing (such as water depth or bottom type) to isolate the effects of the surface conditions and the signal processing so that their dependencies can be studied.

A number of questions are addressed through the analysis of the passive fathometer response with simultaneous wind speed measurements and video of the sea-surface conditions at a fixed array. For example, what are the minimum wind speed (or sea-state) conditions required and what is the dependency of the response on wind or sea-state conditions? The data considered in this article were taken from a longterm deployment that allowed a wide variety of conditions to be studied. A second goal of this work is to describe how the passive fathometer return can provide a quantitative measure of the impedance contrast between the water and the seabed layers. This provides a very simple yet useful measurement for identifying the seabed type (e.g., gravel, sand, mud, etc.). To accomplish this the processing needs to be self-calibrating to remove any dependency on wind speed or sea-state. A deployed system would not be nearly as useful if the impedance estimate required an ancillary wind speed or sea-state measurement.

This paper is organized as follows: The experiment's location, equipment used, and the measured environmental 

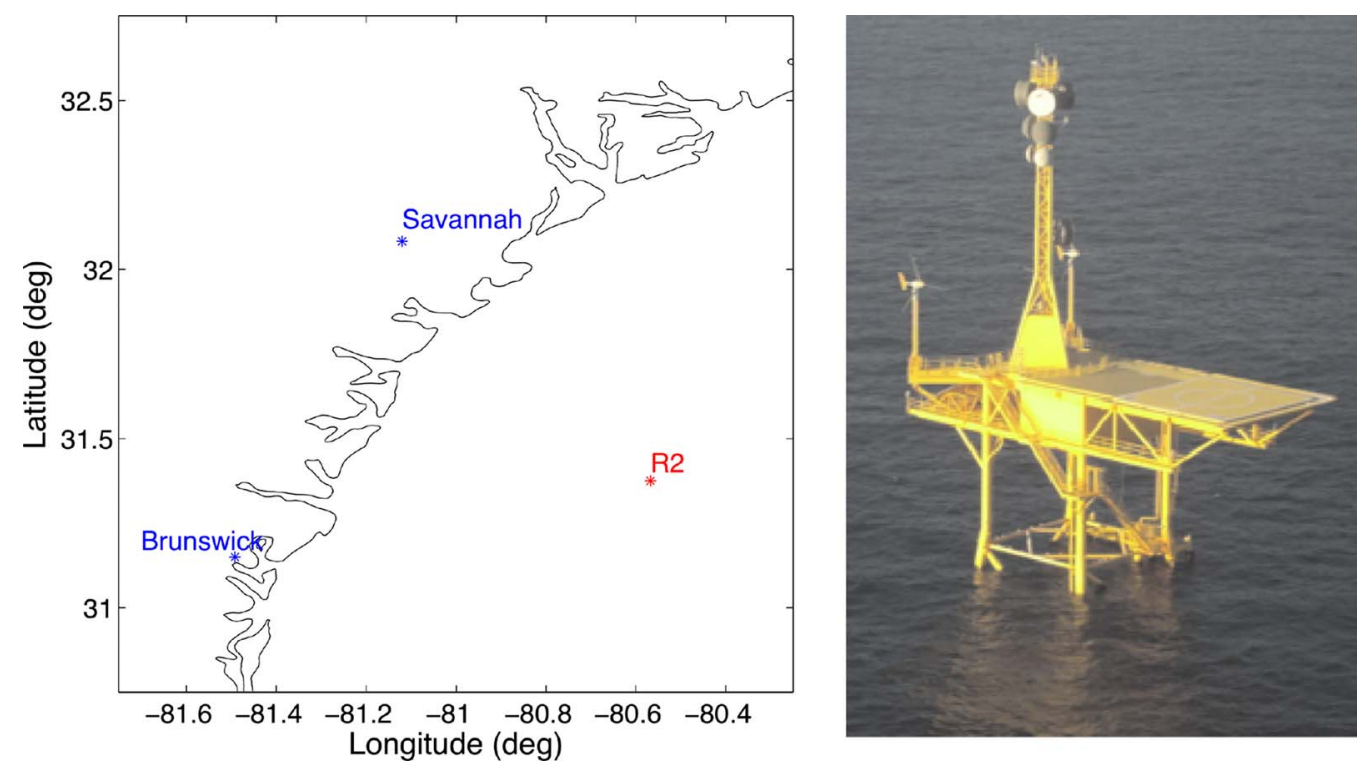

FIG. 1. (Color online) Location of TACTS off-shore range and image of R2 tower.

parameters are presented in Sec. II. In Sec. III, an overview of the processing used to obtain the passive fathometer's time-series response is given. The effects of environmental conditions on the fathometer's uncalibrated response are presented and discussed in Sec. IV. An analysis of optimal processing parameters for improved detection of bottom features is presented in Sec. V. A newly developed algorithm to calibrate the fathometer response so that the magnitude of the response from a given bottom feature represents the reflection loss is developed and investigated within Sec. VI. A summary of the research findings concludes this paper in Sec. VII.

\section{EXPERIMENTAL MEASUREMENTS}

In January 2006 a 32-hydrophone, three-nested aperture array was deployed near an offshore platform (see Fig. 1). The platform, R2, is one of a range of offshore towers operated by the Navy as a part of a Tactical Air Combat Training System. The tower is located in the shallow waters $(25 \mathrm{~m})$ approximately $75 \mathrm{~km}$ off the coast of Savannah, GA and extends $50 \mathrm{~m}$ above the water surface. The tower is equipped to supply power through solar panels, wind turbines, and a diesel generator. Additionally, it is equipped with two-way microwave communication back to shore, which allowed for long-term measurements while controlling the data acquisition from land via the internet.

The array had hydrophone spacings of $1,0.5$, and $0.25 \mathrm{~m}$ yielding design frequencies of 750, 1500, and $3000 \mathrm{~Hz}$, respectively. Figure 2 illustrates the $15-\mathrm{dB}$ down end-fire beam radius of the innermost aperture on the ocean bottom, used in the analysis presented here.

A high-resolution video camera was installed at the top of the tower ( $\sim 50 \mathrm{~m}$ above water surface). It allowed timesynchronized monitoring of the ocean's surface above the vertical acoustic array. The camera and lens were calibrated using the camera calibration toolbox for MATLAB (Ref. 4) software so that the obtained images could then be georecti- fied to obtain an overhead view of the surface above the array.

In addition to the acoustic and video measurements, the Skidaway Institute of Oceanography, as a component of the South Atlantic Bight Synoptic Offshore Observational Network, maintains a suite of environmental sensors on the tower. These provide both meteorological and oceanographic measurements, which are available from Skidaway's website. ${ }^{5}$ Of interest here are measurements of wind speed and wave height. Measurements of the tide were also available; however, due to the use of a bottom-fixed array, it had no effect on the results reported here.

\section{PROCESSING}

The passive fathometer is based on the cross-correlation of the surface noise generated by breaking waves and the echo return from the seabed. For a good portion of the frequency band, except lower frequencies dominated by shipping $(\sim 20-200 \mathrm{~Hz})$, the breaking waves are commonly the predominant source of ambient noise (up to $\sim 30 \mathrm{kHz}$ ). The passive fathometer processing was developed by Siderius et $a l^{3}$ and since the original introduction, a number of efforts ${ }^{6,7}$ have extended and refined the methodology and improved

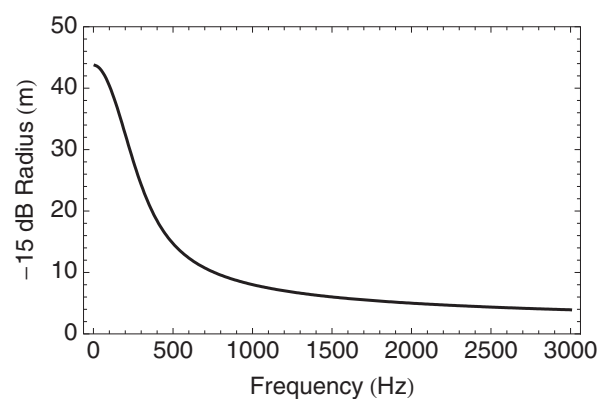

FIG. 2. End-fire beam radius $(-15 \mathrm{~dB})$ of the innermost array aperture at the ocean bottom. This gives an idea of the bottom surface patch size interrogated as a function of frequency. 
the understanding. This work built on the seminal work of Rickett and Claerbout ${ }^{8}$ and Weaver and Lobkis ${ }^{9,10}$ in seismic and ultrasonics as well as Kuperman and co-workers for underwater acoustics. ${ }^{11-14}$

The simplest formulation starts with correlation between a beam in the direction toward the surface with the beam toward the seabed. These beams are formed using an array such as that described in Sec. II. The hydrophone data at frequency $\omega$ are written as a column vector d $=\left[d_{1}, d_{2}, \ldots, d_{M}\right]$ for the $M$ hydrophones. In conventional beamforming, the weight for the $m$ th hydrophone steered at $90^{\circ}$ (in direction toward the surface) is written as

$$
w_{m}=e^{i(m a \omega / c)},
$$

where $a$ is the distance between the equally spaced hydrophones and $c$ is the sound speed in the water (around $1500 \mathrm{~m} / \mathrm{s}$ ). If the surface steering weights are written as a column vector, $\mathbf{w}=\left[w_{1}, w_{2}, \ldots, w_{M}\right]$, the beam directly toward the surface, $B_{\text {up }}$, can be written as

$$
B_{\text {up }}=\mathbf{w}^{\dagger} \mathbf{d},
$$

where $\dagger$ represents the conjugate transpose operation. The steering weights toward the seabed $\left(\right.$ at $-90^{\circ}$ ) are just the conjugate of the weights steered toward the surface. The beam steered directly toward the seabed is then

$$
B_{\mathrm{dn}}=\mathbf{w}^{\mathbf{T}} \mathbf{d},
$$

where $\mathbf{T}$ represents the transpose operation without conjugation. The correlation of the surface steered beam with the seabed steered beam is

$$
C=B_{\mathrm{up}} B_{\mathrm{dn}}^{*}=\left(\mathbf{w}^{\dagger} \mathbf{d}\right)\left(\mathbf{w}^{\mathbf{T}} \mathbf{d}\right)^{*}=\mathbf{w}^{\dagger} \mathbf{d} \mathbf{d}^{\dagger} \mathbf{w}^{*}=\mathbf{w}^{\dagger} \mathbf{K} \mathbf{w}^{*},
$$

where the cross-spectral density matrix (CSDM), $\mathbf{K}$, is identified as a time average of $\mathbf{d d}^{\dagger}$ and * indicates a conjugation. Note that if $\mathbf{w}^{*}$, in Eq. (4), is replaced with $\mathbf{w}$ one obtains the expression for a beam steered toward the surface as opposed to a cross-correlation between upward and downward beams. With the given expression, the CSDM can be formed over as many snapshots of data, $\mathbf{d}$, as needed to obtain the desired averaging. The number of snapshots needed is one of the topics of Sec. V.

An improved fathometer response can be achieved by using adaptive beamforming, or specifically, minimum variance distortionless response (MVDR) ${ }^{15}$ MVDR is useful to suppress the energy coming from directions other than that of interest. In this case there is significant energy coming near horizontal that is of no interest (i.e., snapping shrimp colony on the $\mathrm{R} 2$ tower) for the passive fathometer processing. To adaptively beamform, the MVDR steering weights, $\mathbf{w}_{\mathbf{A}}$, are computed, according to Burdic, ${ }^{16}$ as

$$
\mathbf{w}_{\mathbf{A}}=\frac{\mathbf{K}^{-1} \mathbf{w}}{\mathbf{w}^{\dagger} \mathbf{K}^{-1} \mathbf{w}} \text {. }
$$

The MVDR correlation at frequency $\omega$ is

$$
C=\mathbf{w}_{\mathbf{A}}^{\dagger} \mathbf{K} \mathbf{w}_{\mathbf{A}}^{*} \text {. }
$$

The time-series passive fathometer response is the inverse Fourier transform of $C$ or $r(t)=\mathcal{F}^{-1}\{C(\omega)\}$. Strictly, this

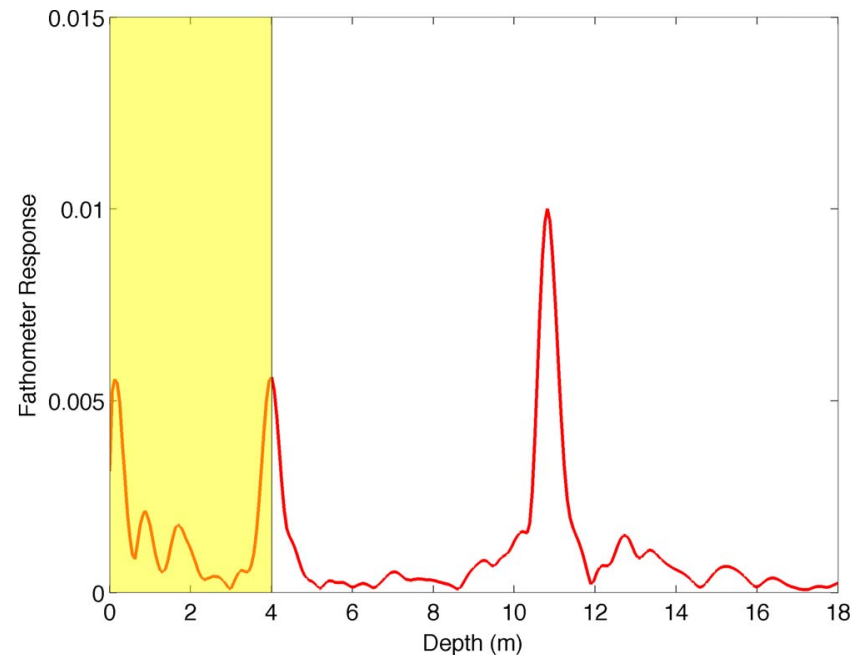

FIG. 3. (Color online) Uncalibrated fathometer response referenced to the top hydrophone at $10.96 \mathrm{~m}$ above ocean bottom as measured at deployment. The shaded area represents the two-way travel time over the length of the array and the response within it may be considered as a processing artifact.

expression is fine if detecting the seabed and layering are all that is of interest. However, if one wants the impulse response of the seabed, $\grave{r}(t)$, then differentiation with time is needed as described by Harrison and Siderius ${ }^{6}$ and Roux et $a l .{ }^{12}$ The Fourier transform of the impulse response, $\grave{r}(t)$, is the reflection coefficient, $R(\omega) .{ }^{17}$ An estimate for the impulse response, $\widetilde{r}(t)$, is then

$$
\widetilde{r}(t)=N \frac{d}{d t} r(t),
$$

where $N$ is an unknown normalization constant, as derived by Harrison and Siderius, ${ }^{6}$ that involves several terms, including the beam width, integration time, and the standard deviation of the noise (related to the sea-state). Some of these terms, such as those that depend on the exact surface conditions, make estimating this factor difficult.

Figure 3 shows a typical, uncalibrated, fathometer response, $r(t)$, for the experiment environment that is referenced to the topmost hydrophone of the innermost aperture. The time axis has been converted to distance using the twoway travel time assuming a sound speed of $1500 \mathrm{~m} / \mathrm{s}$. The initial response within the first $4 \mathrm{~m}$ (shaded box) is a processing artifact that corresponds to the length of the array. ${ }^{3,7}$ The peak at $\sim 11 \mathrm{~m}$ is the response due to the bottom and is in good agreement with the known bottom depth (from the topmost hydrophone) of $10.96 \mathrm{~m}$.

\section{EFFECTS OF SEA-SURFACE CONDITIONS}

Presumably any passive fathometry systems developed in the future will be required to operate in a variety of environmental conditions; thus it is of interest to analyze the impact of the conditions on the processing results. Although of little interest for actual fathometry, the fixed location of the array used here is ideal for such a study. Data sets from 2 days were selected to investigate the environmental effects on the fathometry processing. The first set was acquired on January 14, 2006 over roughly an 8-h time period. The en- 


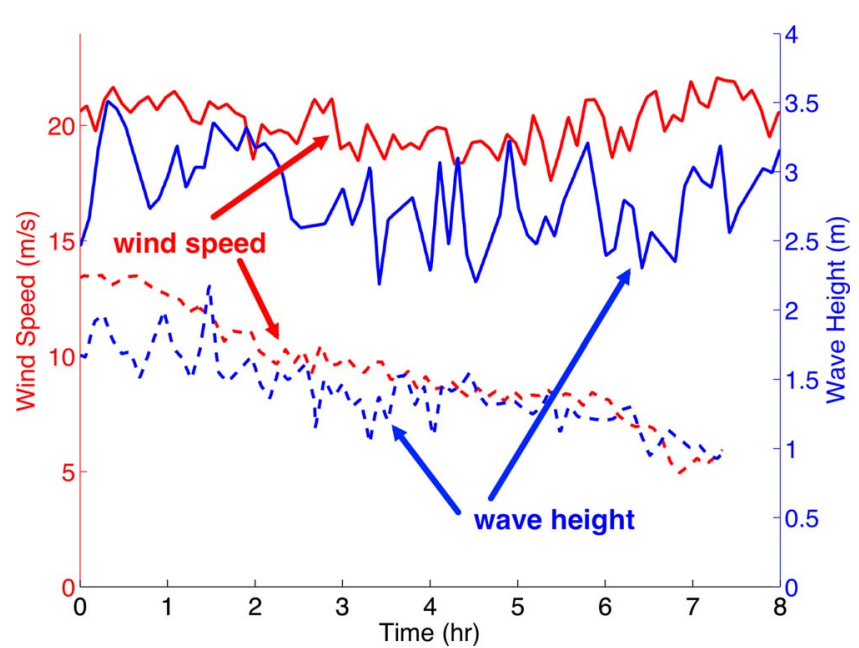

FIG. 4. (Color online) Wind speeds and wave heights for the 2 days analyzed within the study. Solid lines represent wind speeds and wave heights acquired on Julian day 14. Dashed lines were obtained on Julian day 81, in which wind speeds and wave heights declined throughout the day.

vironmental conditions were relatively constant with high winds $(\sim 20 \mathrm{~m} / \mathrm{s})$ and wave heights of $\sim 3 \mathrm{~m}$ (see Fig. 4 ). The second data set was acquired during a time period (March 22, 2006) in which the wind speeds and wave heights dropped over the duration of several hours.

Initial development of this methodology ${ }^{3}$ plausibly assumed that breaking waves were the source that made the processing feasible. This assumption is proven correct here via video images of the sea surface recorded simultaneously with the acoustic data. Figures 5 and 6 show the timesynchronized video images (georectified), upward end-fire beam spectrograms, and normalized fathometer responses (see Sec. V for normalization process) in the absence and in the presence of a breaking wave, respectively. The outlined windows in the spectrogram figures represent the 10-s averaging window, and the video snapshots correspond to its leading edge. It is seen in Fig. 5 that in the absence of a
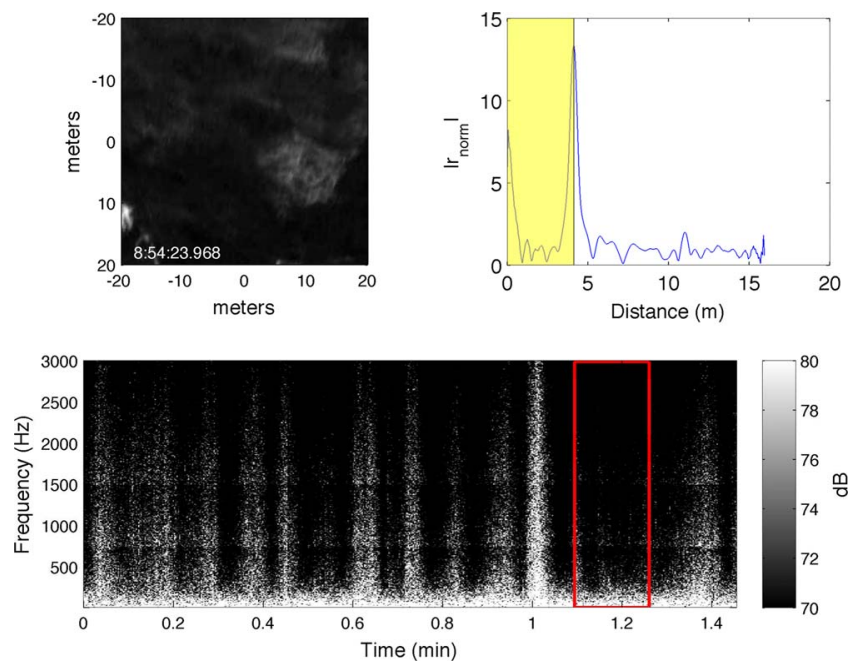

FIG. 5. (Color online) Time-synchronized images of ocean surface video, end-fire beam acoustic array reception, and normalized fathometer response. In the absence of breaking waves (video and acoustic) within a 10-s averaging time window, no fathometer response is observed at the known bottom depth $(10.96 \mathrm{~m})$.
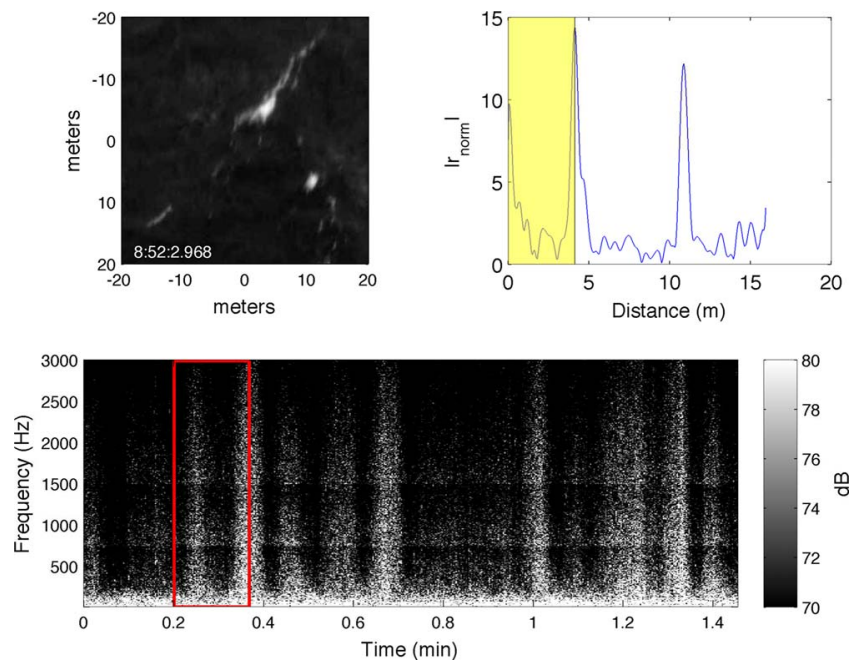

FIG. 6. (Color online) Time-synchronized images of video, end-fire acoustic array reception, and normalized fathometer response. In the presence of breaking waves (video and acoustic) within a 10-s averaging time window, a peak in the fathometer response is observed at the known bottom depth (10.96 m).

breaking wave, within the end-fire beam pattern and the processing averaging time window $(10 \mathrm{~s})$, no fathometer response is seen at the known bottom depth $(\sim 11 \mathrm{~m})$. However, when a breaking wave does occur overhead of the array (see Fig. 6), a strong peak is seen in the fathometer response at the known bottom depth.

In an effort to investigate the effect of wind speed and wave height on the fathometer response, the amplitude of the response at the known bottom location was examined. Figures 7 and 8 show log-log plots of the peak of the unnormalized fathometer response (using an 80-s averaging time) as functions of wind speed and wave height, respectively. The data points plotted as triangles correspond to Julian day 14, in which wind speed remained constant, and the asterisks

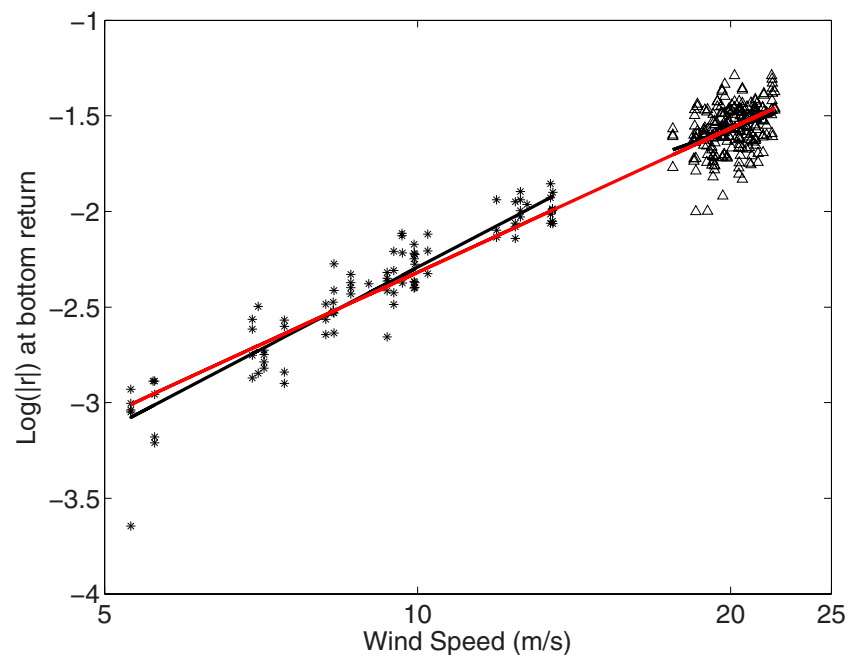

FIG. 7. (Color online) Relationship between wind speeds and the magnitude of raw fathometer response at the bottom return ( 80 -s averaging time). The asterisks represent data taken on Julian day 81 , and the linear best fit has a slope of 2.842 and wind speed correlation of 0.9395 . The triangles represent data taken on Julian day 14, and the linear best fit has a slope of 1.9342 and a correlation of 0.3584 . The linear best fit for the 2 days of data has a slope of 2.503 and a correlation of 0.9445 . 


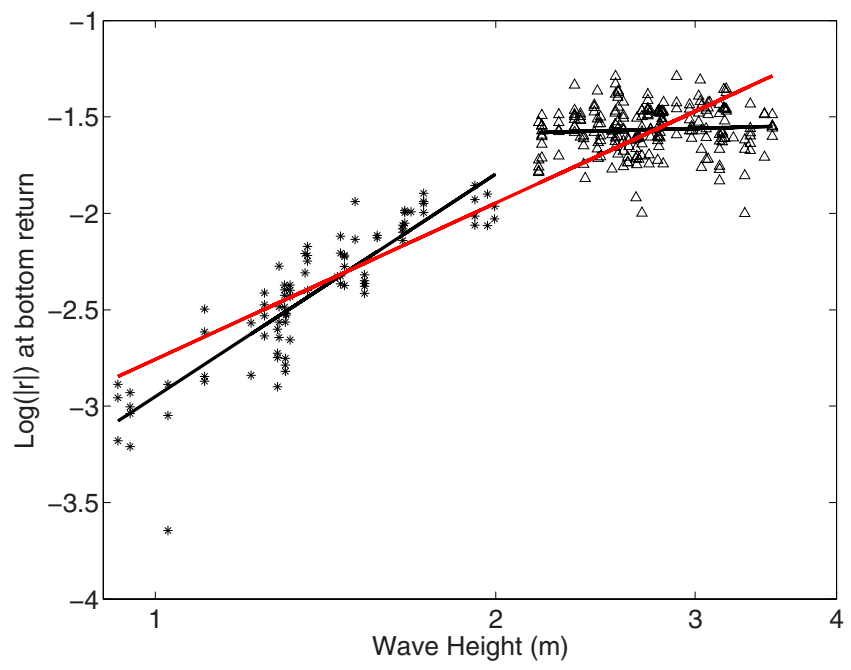

FIG. 8. (Color online) Relationship between wave heights and the magnitude of raw fathometer response at the bottom return (80-s averaging time). The asterisks represent data taken on Julian day 81 , and the linear best fit has a slope of 2.8482 and wind speed correlation of 0.8808 . The triangles represent data taken on Julian day 14, and the linear best fit has a slope of 0.1519 and a correlation of 0.0670 . The linear best fit for the 2 days of data has a slope of 2.6959 and a correlation of 0.9081 .

plot data taken during the declining winds of Julian day 81 . A best-fit line has been inserted for both data sets. In comparing the two figures and linear best fits, it is seen that the fathometer response is better correlated with wind speed than wave height. [Correlations are 0.9445 (JD 14 and 81) with wind speed versus 0.9081 (JD 14 and 81) with wave height.] The linear nature of the relationship between the fathometer response with the wind speed, as plotted, seems to follow observed relationships between noise level and wind speed. ${ }^{18}$ Mixed-sea conditions were observed (via video) during much of the acquisition on Julian day 14, which is a plausible explanation for the higher variability in the fathometer response as a function of both wind speed and wave height.

\section{NORMALIZATION, OPTIMIZATION, AND DETECTABILITY}

In practice there are a few signal processing parameters which can be adjusted to optimize the fathometer processing for a given environment. Two of importance are the length of fast Fourier transform (FFT) (snapshot size) and the averaging time (number of snapshots). First of all, the FFT length must be selected so that sufficient travel time is allowed for the propagation to and from the bottom, and any sub-bottom features of interest.

In addition to adjusting processing parameters, one may also choose to normalize the fathometer response. This allows comparing one result to another or determining optimal performance for given conditions. A better understanding of the detectability of bottom and, presumably, sub-bottom returns may be gained by normalizing the fathometer response. The normalization chosen here is the mean of the "noise" background between the initial processing artifacts (i.e., travel along the length of the array) and the response due to the bottom return. This occurs over depths between $\sim 5$ and $10 \mathrm{~m}$, as seen in Fig. 3.

Figures 9(a) and 9(b) show the magnitude of the peak in the normalized fathometer response, $\left|r_{\text {norm }}\right|$, as a function of averaging time for different wind speeds with FFT lengths of 2.73 and $0.17 \mathrm{~s}$, respectively. Each curve represents the mean of 15-20 time segment samples (with averaging times as indicated) within an hour time period. It is evident that for longer FFT lengths, Fig. 9(a), a longer averaging time is necessary to obtain a more distinct peak. However, for the shorter FFT lengths, Fig. 9(b), the peak's magnitude begins to plateau at shorter averaging times. Additionally, lower wind speeds (though, still with wave breaking) and longer FFT lengths may require long averaging times to observe the bottom return.

Figure 10 shows the uncalibrated fathometer response amplitude at the bottom return and the normalization factor
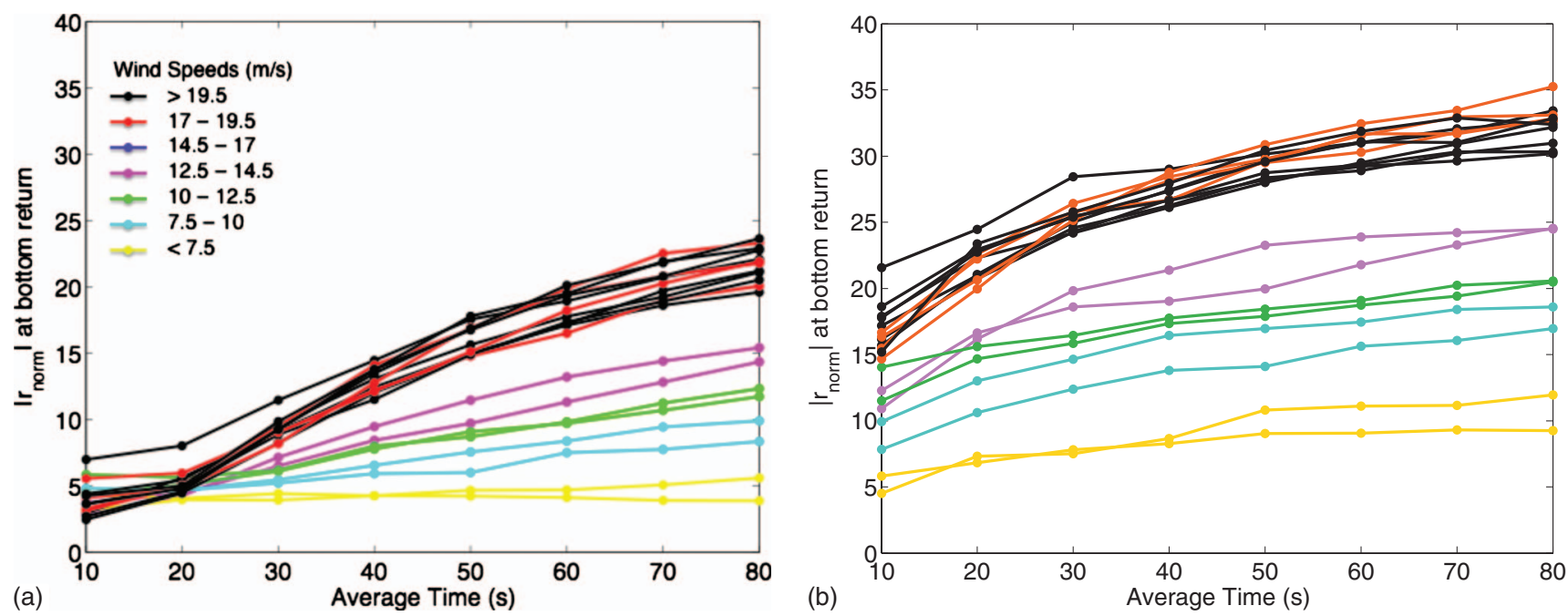

FIG. 9. Magnitude of normalized fathometer response at bottom return as a function of averaging time using adaptive beamforming for a range of wind speeds. Panel (a) was processed with an FFT length of $2.73 \mathrm{~s}$; panel (b) was processed with an FFT length of 0.17 s. It is evident that shorter FFT lengths achieve higher detectability with shorter averaging times, which would provide better resolution in a drifting fathometer system in ocean conditions with less frequent wave breaking. 


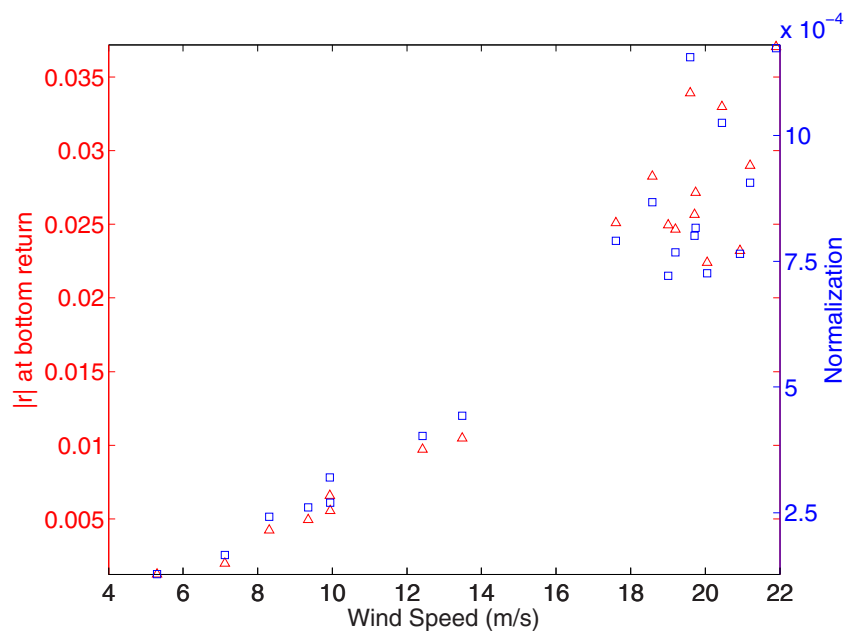

FIG. 10. (Color online) Magnitude of uncalibrated fathometer response peaks (triangles) and normalization factors (squares) as a function of wind speed using adaptive beamforming and 80 -s averaging time with FFT length of $0.17 \mathrm{~s}$.

as a function of wind speed. It is seen that as wind speed increases the peaks become more detectable as the ratio of the raw response and the normalization factor becomes larger.

Although it is plausible that the normalization used here would remove the dependence on wind speed (or wave height) on the fathometer response, it proves not to be the case. Figure 11 shows the magnitude of the normalized fathometer response at the bottom return along with the wind speeds for the two time periods. It is seen that the response still tracts with the wind speed.

As discussed in Sec. III, adaptive beamforming is used here primarily. However, to illustrate the improvement this allows, Fig. 12 shows the magnitude of the fathometer response as a function of averaging time and wind speeds when conventional beamforming is employed, rather than

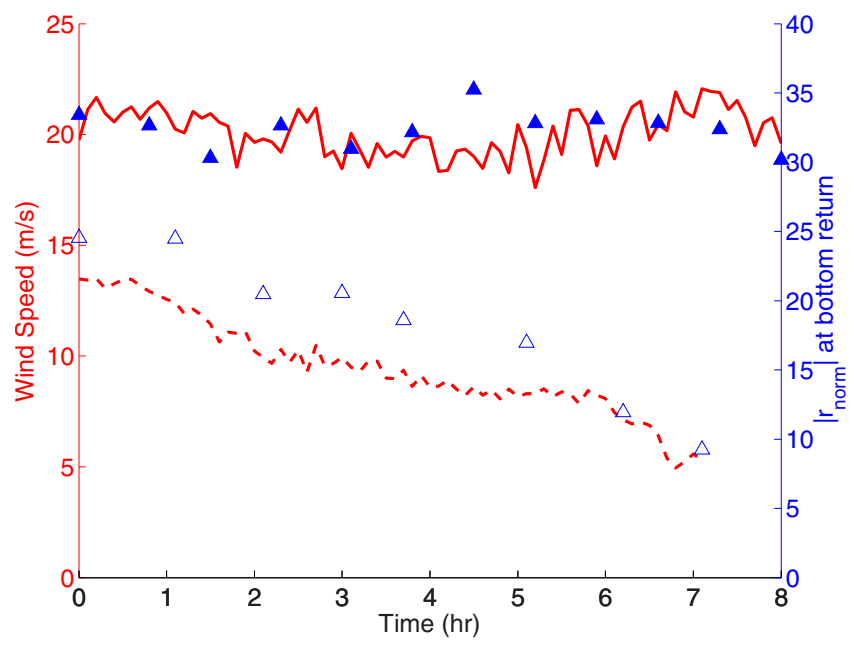

FIG. 11. (Color online) Wind speed and magnitude of normalized fathometer response as a function of time with FFT length of $0.17 \mathrm{~s}$ and an averaging time of $80 \mathrm{~s}$. Solid line and triangles represent wind speeds and power reflection losses acquired on Julian day 14. Dashed lines and open triangles were obtained on Julian day 81, in which wind speeds and wave heights declined throughout the day. The normalized fathometer response tracks with the wind speed.

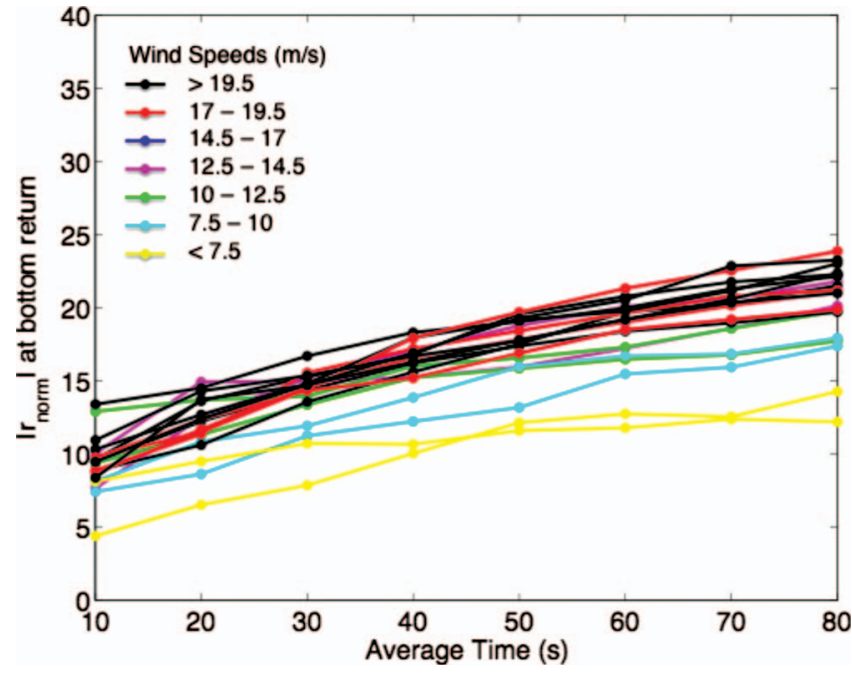

FIG. 12. Magnitude of normalized fathometer response as a function of averaging time with FFT length of 0.17 s using conventional beamforming.

the adaptive beamforming which is used in Fig. 9(b). It is seen that for conventional beamforming, additional averaging time would be necessary to maximize the detectability of returns within the fathometer response.

\section{CALIBRATED RESPONSE}

One may also choose to normalize the fathometer response so that the return is a direct estimate of the bottom impulse response $\widetilde{r}(t) \approx \grave{r}(t)$. This will be referred to as the calibrated passive fathometer response and ideally is independent of wind speed or sea-state. With $r(t)$, the value at any peak represents the reflection coefficient at that interface. Recall from Eq. (7) that the estimate of the impulse response $\widetilde{r}(t)$ is related to the cross-correlation through a timederivative and an unknown factor $N$. To determine $N$, the relationship developed by Harrison and Simons ${ }^{2}$ for estimating the magnitude-squared reflection coefficient in terms of the beam powers can be used,

$$
|\widetilde{R}|^{2}=\frac{\left|B_{\mathrm{up}}\right|^{2}}{\left|B_{\mathrm{dn}}\right|^{2}} .
$$

The power in the time and frequency domains is the same; therefore,

$$
\int_{-\infty}^{\infty}|\grave{r}(t)|^{2} d t=\int_{-\infty}^{\infty}|R(\omega)|^{2} d \omega .
$$

The estimated value for $N$ is determined using Eqs. (8) and (7),

$$
N=\sqrt{\frac{\int_{-\infty}^{\infty}|\widetilde{R}(\omega)|^{2} d \omega}{\int_{-\infty}^{\infty}|(d / d t) r(t)|^{2} d t}} .
$$

In practice, the integration limits used are based on the available bandwidth and array geometry (i.e., hydrophone spacing). The reflection coefficient between two media at normal incidence is defined as 


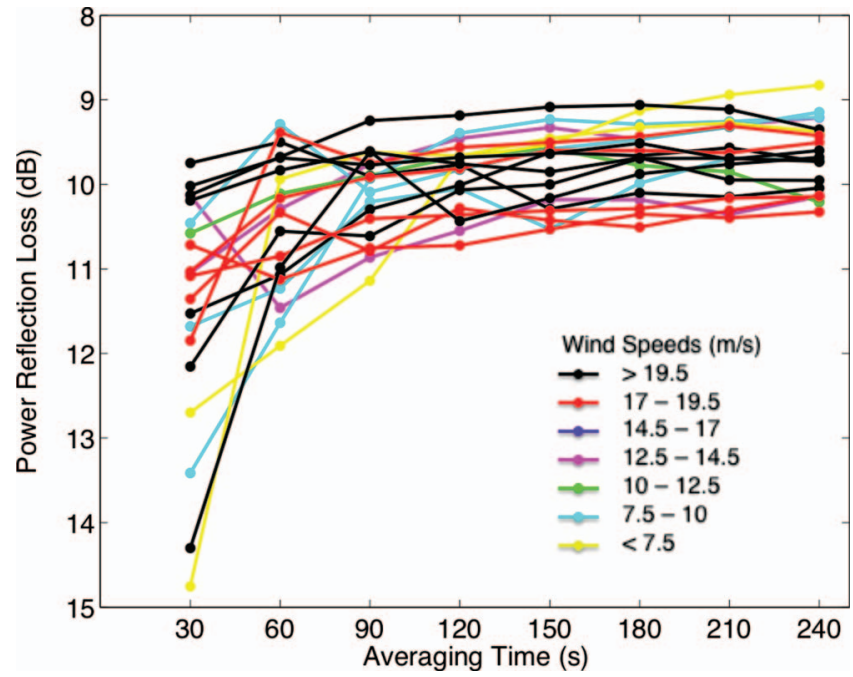

FIG. 13. Calibrated fathometer response (power reflection loss), via coherent processing, as a function of averaging time. This is in good agreement with the mean power reflection loss of $7.8 \mathrm{~dB}$ at vertical incidence, as determined by Eq. (8), for frequencies between 500 and $2800 \mathrm{~Hz}$.

$$
R=\frac{Z_{2}-Z_{1}}{Z_{2}+Z_{1}}
$$

where $Z_{1}$ and $Z_{2}$ are the impedance values in the two media (e.g., water and seabed) which are $Z_{1}=c_{1} \rho_{1}$ and $Z_{2}=c_{2} \rho_{2}$ for sound speeds, $c_{1}$ and $c_{2}$, and densities, $\rho_{1}$ and $\rho_{2}$. The time domain version of the reflection coefficient, $\widetilde{r}(t)$, is useful since the peak values give the impedance at the water-seabed interface as well as between sub-bottom layers. Using Eq. (10) in Eq. (7) results in a type of calibration for the passive fathometer time-series that should not depend on factors such as integration time and sea-state. Figure 13 shows the calibrated fathometer response peak (magnitude-squared in decibels) as a function of averaging time and wind speeds. This represents the reflection loss, and the figure shows reasonable stability in the estimate over a large range of wind speeds once the averaging is above about $1 \mathrm{~min}$.

This case is somewhat trivial since there is only one peak in the fathometer return; however, in principle this should provide the impedance contrast value for additional layers using this process. The bottom loss (i.e., $-10 \log \left(|R|^{2}\right)$ ) at vertical incidence was also calculated using the frequency domain calculation given by Eq. (8). This was integrated over frequencies from 500 and $2800 \mathrm{~Hz}$ to produce a loss estimate of $7.8 \mathrm{~dB}$. If there were significant layering, however, there would be a complicated interference pattern in the frequency domain reflection coefficient. Integration of the reflection coefficient over frequency would not represent the loss at any of the individual layers, just the integrated loss over frequency through the entire seabed.

For this impedance estimating methodology to be useful in practical applications, it must yield values which are invariant to environmental conditions. Figure 14 shows the magnitude of the calibrated fathometer response (in decibels) for different times and wind speeds. It is seen that the reflection loss varies by less than $0.3 \mathrm{~dB}$ when an averaging time of $80 \mathrm{~s}$ is used.

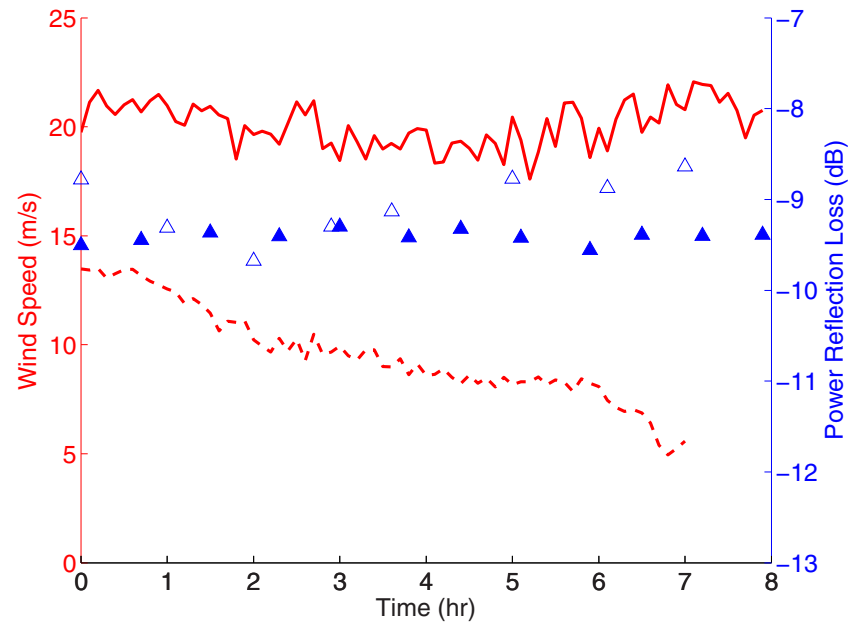

FIG. 14. (Color online) Wind speed and magnitude of calibrated fathometer response as a function of time with FFT length of $0.17 \mathrm{~s}$ and an averaging time of $240 \mathrm{~s}$. The solid line is wind speed data acquired on Julian day 14 and solid triangles are the corresponding reflection loss value. Dashed line is wind speed for Julian day 81, with open triangles indicating the corresponding reflection loss values.

Comparison of the fathometer response can be made with sediment measurements made during the Tactical Air Combat Training System (TACTS) tower construction (see Table I). ${ }^{19}$ The estimated sound speeds and densities are obtained from an APL-UW handbook ${ }^{20}$ using the description of the layers within the core sample. Previous analysis by Siderius et $a l^{3}$ of data obtained above a softer bottom has shown that the passive fathometer was capable of detecting sub-bottom layering within the sediment to $25 \mathrm{~m}$ beneath the bottom. Although sub-bottom layering is present in the core samples drawn prior to tower construction, no sub-bottom layering is observed via the passive fathometer. It is likely that the large impedance mismatch, due to the sandy bottom, prevents the detection of sub-bottom layering. However, note that the impedance from the table values [Layer 1 reflection loss: 8.6-12.6 dB using Eq. (11)] is in relatively good agreement with the reflection loss values estimated here from the calibrated passive fathometer response.

\section{SUMMARY AND CONCLUSIONS}

The main emphasis of this paper has been to determine the effect of environmental conditions on passive fathometer

TABLE I. Core sample description and estimated sound speeds and densities.

\begin{tabular}{clccc}
\hline \hline Layer & Description & $\begin{array}{c}\text { Depth } \\
(\mathrm{m})\end{array}$ & $\begin{array}{c}\text { Est. sound speed } \\
(\mathrm{m} / \mathrm{s})\end{array}$ & $\begin{array}{c}\text { Est. density } \\
\left(\mathrm{kg} / \mathrm{m}^{3}\right)\end{array}$ \\
\hline 1 & $\begin{array}{l}\text { Gray calcareous fine to } \\
\text { medium sand }\end{array}$ & 0.0 & $1660-1767$ & $1451-1845$ \\
2 & $\begin{array}{l}\text { Greenish gray carbonate } \\
\text { silty fine sand }\end{array}$ & 4.88 & 1660 & 1451 \\
3 & Sandy clay & 14.0 & 1477 & 1147 \\
4 & Hard silty clay & 24.70 & 1473 & 1146 \\
5 & $\begin{array}{l}\text { Hard calcareous olive } \\
\text { gray sandy clay }\end{array}$ & 76.22 & 1477 & 1147 \\
\hline \hline
\end{tabular}

${ }^{\mathrm{a}}$ Reference 20 . 
processing techniques. The analysis was focused on determining optimal processing parameters over a range of wind speeds and sea-states to aid the development of practical passive fathometer systems. It was determined that for a given depth of interest, shorter FFT lengths yield more detectable bottom returns with less averaging time. Thus, for practical moving systems, higher-resolution fathometry can be performed when shorter FFT lengths are used. It was also observed that the adaptive beamforming methods (e.g., MVDR) yielded increased performance. Additionally, a new self-calibrating methodology was proposed such that the magnitude of fathometer response peaks yield estimates of reflection coefficients of bottom and sub-bottom interfaces. It was shown that the proposed technique yielded valid results independent of wind speed.

\section{ACKNOWLEDGMENTS}

This work was supported by Office of Naval Research base funding at the Naval Research Laboratory.

${ }^{1}$ M. J. Buckingham, B. V. Berkhout, and S. A. L. Glegg, "Imaging the ocean with ambient noise," Nature (London) 356, 327-329 (1992).

${ }^{2}$ C. H. Harrison and D. G. Simons, "Geoacoustic inversion of ambient noise: A simple method," J. Acoust. Soc. Am. 112, 1377-1389 (2002).

${ }^{3}$ M. Siderius, C. H. Harrison, and M. B. Porter, "A passive fathometer technique for imaging seabed layering using ambient noise," J. Acoust. Soc. Am. 120, 1315-1323 (2006).

${ }^{4}$ http://www.vision.caltech.edu/bouguetj/calib_doc (Last viewed 9/11/ 2009).

${ }^{5}$ http://www.skio.usg.edu/Skioresearch/physical/sabsoon (Last viewed 9/11/2009).

${ }^{6} \mathrm{C}$. H. Harrison and M. Siderius, "Bottom profiling by correlating beamsteered noise sequences,” J. Acoust. Soc. Am. 123, 1282-1296 (2008).

${ }^{7}$ P. Gerstoft, W. S. Hodgkiss, M. Siderius, C.-F. Huang, and C. H. Harrison,
"Passive fathometer processing," J. Acoust. Soc. Am. 123, 1297-1305 (2008).

${ }^{8}$ J. Rickett and J. Claerbout, "Acoustic daylight imaging via spectral factorization: Helioseismology and reservoir monitoring," The Leading Edge 18, 957-960 (1999).

${ }^{9}$ R. L. Weaver and O. I. Lobkis, "Ultrasonics without a source: Thermal fluctuation correlations at $\mathrm{mHz}$ frequencies," Phys. Rev. Lett. 87, 134301 (2001).

${ }^{10}$ O. I. Lobkis and R. L. Weaver, “On the emergence of the Green's function in the correlations of a diffuse field," J. Acoust. Soc. Am. 110, 3011-3017 (2001).

${ }^{11}$ P. Roux, W. A. Kuperman, and the NPAL Group, "Extracting coherent wave fronts from acoustic ambient noise in the ocean," J. Acoust. Soc. Am. 116, 1195-2003 (2004)

${ }^{12}$ P. Roux, K. G. Sabra, and W. A. Kuperman, "Ambient noise cross correlation in free space: Theoretical approach," J. Acoust. Soc. Am. 117, 79-83 (2005).

${ }^{13}$ K. G. Sabra, P. Roux, and W. A. Kuperman, "Arrival-time structure of the time-average ambient noise cross-correlation function in an oceanic waveguide," J. Acoust. Soc. Am. 117, 164-174 (2005).

${ }^{14}$ K. G. Sabra, P. Roux, and W. A. Kuperman, "Emergence rate of the time-domain Green's function from the ambient noise cross-correlation function," J. Acoust. Soc. Am. 118, 3524-3530 (2005).

${ }^{15}$ M. Siderius, "Analysis of passive seabed imaging techniques (a)," J. Acoust. Soc. Am. 123, 3629 (2008).

${ }^{16}$ W. S. Burdic, Underwater Acoustic System Analysis (Prentice-Hall, Englewood Cliffs, NJ, 1984).

${ }^{17}$ F. B. Jensen, W. A. Kuperman, M. B. Porter, and H. Schmidt, Computational Ocean Acoustics (American Institute of Physics, New York, 1994).

${ }^{18}$ B. R. Kerman, D. L. Evans, D. R. Watts, and D. Halpern, "Wind dependence of underwater ambient noise," Boundary-Layer Meteorol. 26, 105113 (1983).

${ }^{19}$ McClelland Engineers, Inc., Ocean Bottom Survey, Air Combat Training Range, Naval Air Station Field and Laboratory Report No. 0813-0932, Brown and Root Development, Inc., Houston, TX, 1984.

${ }^{20}$ APL-UW High-Frequency Environmental Acoustic Models Handbook (Applied Physics Laboratory, University of Washington, Seattle, WA, 1994), APL-UW TR 9407, p. 128. 